Article

\title{
Critical Factors behind Construction Delay in Petrochemical Projects in Saudi Arabia
}

\author{
Abdullah Rasheed Alhajri ${ }^{1, *}$ and Adel Alshibani ${ }^{2}$ \\ 1 Construction Engineering and Management, KFUPM, Dhahran 31261, Saudi Arabia \\ 2 Architectural Engineering Department KFUPM, Dhahran 31261, Saudi Arabia; alshibani@kfupm.edu.sa \\ * Correspondence: g200579410@kfupm.edu.sa; Tel.: +966-561-637-793
}

Received: 13 May 2018; Accepted: 18 June 2018; Published: 25 June 2018

\begin{abstract}
This paper presents a study conducted to identify, assess, rank, and compare the most influencing factors causing schedule delays during the construction phase of petrochemical projects in Saudi Arabia. The methodology followed in this research to achieve the main aims is a combination of the comprehensive review of the literature and the interviewing of a number of local experts, which have resulted in identifying 23 factors. A total of 90 completed responses were gathered from 106 received responses. The study found that the most influencing factors causing schedule delays during the construction of petrochemical projects in Saudi Arabia are "Poor site management and supervision by contractors"; "Conflict between the main contractor and subcontractor"; "Poor planning and scheduling of projects by the contractor"; "Delays in material or equipment delivery"; and followed by "Delays in Handing Over Construction Site to the Contractor". This paper is original in the sense that the areas of knowledge and practice covered in the identified factors were distributed and not available in one source. The factors are derived from personal interviews with selected project managers, project engineers, construction supervisors, and the others from different positions in the project department and from the relevant literature.
\end{abstract}

Keywords: petrochemical projects; critical factors; schedule delay

\section{Introduction}

Petrochemicals industries are very crucial in our daily life today. It requires the investment of a huge capital annually on different construction projects. These type of construction projects are impacted mostly during the construction phase, which may lead to cost overrun and/or time delay, which results in millions of dollars of losses. Over time, petrochemicals became an essential material for many varieties of downstream products such as rubbers, plastics, polyvinyl chloride (PVC), clothes, kids' toy, and fertilizers, and so forth. Indeed, the need for petrochemical increased for the last thirty years. Nevertheless, the huge demand for petrochemicals material in the whole world led to the expansion of existing plants and the construction of new ones. For example, Saudi Basic Industries Corporation (SABIC) has many mega projects and expansions of existing plants. Those projects are unique in nature and are usually handled by large, specialized Engineering, Procurement and Construction (EPC) contractors, who do both design and construction. In addition to these projects, there are many other projects that do not require many specialties and are considered normal and can be designed and constructed by the company's own force or by local general contractors.

The petrochemical industry is similar to the Oil and Gas industry. It invests enormous capital annually on different projects. Those projects pass through different phases much like any typical project including initiation, planning, engineering, procurement, construction, and close out. Any phase of those can be impacted by different factors, which can affect the whole project cycle. Apparently, those projects are impacted mostly during the construction phase, which leads to cost overrun and/or 
time delay and, consequently, causes millions of dollars in losses. Therefore, the goals of this research paper are to identify, assess, rank, and compare the most influencing factors causing schedule delays during the construction phase of petrochemical projects in Saudi Arabia.

\section{Research Problem and Significance of the Research.}

The main objectives of the project management team during the construction phase are to complete the project within its budget and on time and in accordance with specifications and quality requirements. Hence, identifying and ranking the factors that may cause schedule delays is essential in assisting the project management team to meet the above-stated objectives and to avoid delays. Due to its complexity, in recent years, many petrochemical projects were completed behind the targeted date that was agreed on between the owners and contractors. Such delays have significant consequences for the owners as well as the contractors. The delay during the construction phase is influenced by many factors that make meeting the set date a difficult task to the project management team. The literature reveals that very limited studies have reported on the identifying factors affecting the project schedule during the construction phase in petrochemical projects. This paper aims to identify, assess, rank, and compare the most influencing identified factors causing a delay in the petrochemical projects in the Eastern province of Saudi Arabia. The identification and ranking of such factors can assist owners, contractors, and the project management team of this class of projects in the following:

- Preparing a more realistic and accurate project cost and schedule.

- Completing the project on time and avoiding schedule delays.

- Taking the necessary steps and actions in advance to avoid such delays.

- Giving more attention to the most crucial factors.

\section{Research Methodology}

The research methodology used to achieve the above-stated objectives involve a sequence of steps. It includes the following:

- Conducting a comprehensive literature review to identify the factors that cause schedule delays during the construction phase of petrochemical and similar projects.

- Determining unreported factors based on interviewing the local experts who are involved in the construction of petrochemical projects in Saudi Arabia.

- Combining the identified factors from the literature with that obtained from interviewing project engineers/managers.

- Designing and developing a questionnaire survey to be used for collecting feedback from experts regarding the importance of the identified factors.

- Conducting a pilot study with experts to assess the identified factors and to evaluate the developed questionnaire survey before sending it to the targeted professionals.

- Distributing the questionnaire survey to the population of 106 professionals working in this class of projects in the eastern province of Saudi Arabia.

- Analyzing the data received using the statistical analysis method to identify the level of importance for the identified factors.

- Obtaining the important index value and the rank of each factor.

- Drawing conclusions and recommendations based on the obtained results.

\section{Previous Studies}

Delays in the construction schedule is a major concern for owners and contractors. It can lead to cost overruns and costly disputes. The literature reveals that a lot of research has been conducted over the years to find the causes of such delays in the construction industry in general; for example [1-5]. In oil and gas construction projects, the project size is large and requires a considerable capital investment 
and lengthy duration. This class of projects comprises of three main phases; the conceptual phase; the front-end engineering and design (FEED) phase; and the engineering, procurement, and construction (EPC) phase [1]. According to the survey conducted by Salama, et al. [5], the EPC is the most significant phase that should be closely monitored and controlled in order to prevent time slippages and improve the overall project performance. Accordingly, on-time completion is a high priority for both clients and contractors [6]. Khan [7] highlighted that the main two common objectives of any construction management team are to reduce the project time and the cost required for the implementation of a project. In addition, the literature reveals that the delay in construction projects is a common problem worldwide for the different types of industries and that it is one of the most common problems in the construction industry [8].

Alinaitwe, et al. [8] found that the five critical factors of delays in construction industry projects are scope variation, progress payment delay, the weak project control system, the high cost of the project and political insecurity, and instability. Rao [9] identified the major causes of schedule delays in construction projects from different parties including the owner, contractor, designer, and external party. The author then ranked the identified factors and found that the most significant factors that cause delays from all perspectives are the delays in making the payments; lack of communication between parties; late issue of instruction; poor management contractors and execution; delays in approving design document; delays due to the shortage of materials and price fluctuations. Ruqaishi and Bashir [10] have identified seven major factors responsible for project delays in the construction phase where Poor site management and supervision by contractors are found to be the 1st factor. Raykar and A. N. [11] were in agreement with this finding as well for construction projects in general. While others like Rao [10] ranked this as number four in his list and Mydin, et al. [12] ranked it as the third factor. The nd critical factor, as identified by Ruqaishi and Bashir [5], is problems with subcontractors, which was identified as well by Raykar and A. N. [11] to be the nd factor. The poor projects scheduling and planning by contractors is the 3rd factor (Ruqaishi and Bashir [10] and Raykar and A. N. [11]. However, Khan [7] ranked inadequate planning to be number 4th in the list. The poor management of contractors' schedules and execution has been identified to be the 4 th critical factor by Ruqaishi and Bashir [10], followed by delays in the delivery of materials as the 5th factor, but Raykar and A. N. [11] found it to be the 4th critical factor.

Furthermore, Ruqaishi and Bashir [11] indicated that the lack of effective communication among project stakeholders is ranked as number six in top critical causes, while Rao [9] identified this to be the second critical factor and Raykar and A. N. [11] classified it as the 5th factor. The last and 7th factor by Ruqaishi and Bashir [11] is the poor engagement with equipment suppliers in the engineering and procurement stages. Mydin, et al. [12] found that the delays caused by contractors was ranked first, then those by consultant factors, followed by client causes, and those caused by external causes was ranked last. Other factors such as the scope of work, change in weather, equipment cost and usage, cash flow, and decision-making policy have an impact as well (Raykar and A. N. [11]). The literature clearly shows that not too many studies have been reported in identifying, assessing, ranking, and comparing the most influencing factors causing schedule delays during the construction phase of Petrochemical Projects. Salama, et al. [6] have stated that the most critical factors occur during the EPC phase for gas and oil projects are the lateness of material delivery, wrong and inadequate processes of selecting the right contractor during the bidding stage of FEED or EPC by laying more emphasis on the bid value rather than on the contractor's competencies, ineffective communication systems, and shortages in experienced manpower. Khan [7] identified the top five factors that cause schedule delays in gas and oil projects. Those factors are changes in scope, the poor procurement process, lack of qualified laborers, poor planning and scheduling, inexperienced contractors, and bad performance by the subcontractors.

Furthermore Hwang and Leong [13] have identified that the factors causing delays in projects which are the following: (1) quick decision making by the client; (2) quick decision making involving all the project teams; (3) communication/coordination between key parties; (4) the experience of consultants; and (5) difficulties in funding or any finance related to the project by contractors. 
Additionally, another paper by Hwang, et al. [14] found that the contractor management at the site, the coordination between project parties and the shortage of laborers at the site are the top factors causing schedule delays in housing projects in Singapore.

\section{Identifying Factors Causing Construction Delay in Petrochemical Projects}

The 21 factors are identified from the literature reviews and two more factors were identified by interviewing local experts as shown in Table 1. The factors obtained from experts are site handover delays to contractors and delays in getting work permits from the government. Those factors are to be tested in this research against those projects implemented in the petrochemical industry. The factors drawn from the literature cause delays in the petrochemical projects along with a short explanation of each factor are presented below.

\subsection{Poor Site Management and Supervision by Contractors}

During construction, contractors want to get the project done as efficiently and quickly as possible but if the timeline is too aggressive, it will result in more accidents; more mistakes; cut corners; and overworked, unhappy, and unproductive employees.

\subsection{Conflict between Main Contractor and Subcontractor}

Poor construction management also results due to poor subcontractor selection. This leads to conflict between the two parties.

\subsection{Inadequate Planning and Scheduling of Projects by the Contractor}

Project planning is defined as a set of established processes used to make a decision on what tasks must be performed to achieve the project's set objectives within schedule and budget. Scheduling is setting those processes and steps in a timeline toward the agreed completion date.

\subsection{Delay of Material or Equipment Delivery}

This is related to long lead materials, which usually takes months to be delivered, which can potentially affect the project if the order is not placed in earlier and at the right time.

\subsection{Delay in Handing over Construction Site to the Contractor}

On the commencement of the main contract to construct the works, the client hands over possession of the site and the contractor's work area(s) to the contractor. This handover procedure may take place at a formal handover meeting.

\subsection{Shortage of Material and/or Equipment}

A situation where the available quantity of the required material falls short of the quantity demanded or required at a given time or price.

\subsection{Shortage of Skilled Laborers for the Contractor}

Skilled labor in the construction industry specifically refers to labor that requires workers who have specialized training or a learned skill-set to perform the work. These workers can have varied levels of training or education. In many cases, skilled laborers are those who have received enough training to become certified in a particular trade field.

\subsection{Weather Effects}

Bad weather conditions usually affect the construction project. For example, heavy rains, sandstorms, extremely hot weather, humidity, and so forth may affect the labor productivity and eventually delay the project schedule. 
Table 1. The summary of the factors drawn from the literature and local experts.

\begin{tabular}{|c|c|c|c|c|c|c|c|c|c|c|c|c|c|c|c|c|}
\hline & \multirow{2}{*}{ Potential Factors } & \multicolumn{15}{|c|}{ Resources Reference Number } \\
\hline & & [1] & [2] & [3] & [4] & [5] & [6] & [7] & [8] & [9] & [10] & [11] & [12] & [13] & [14] & [15] \\
\hline 1. & Poor site management and supervision by contractors & $X$ & $X$ & $X$ & $X$ & & $x$ & $x$ & $x$ & $X$ & $x$ & $x$ & & & $x$ & $x$ \\
\hline 2. & Conflict between the main contractor and subcontractor & & $X$ & $X$ & & & $X$ & & & & & & & & & \\
\hline 3. & Inadequate planning and scheduling of projects by the contractor & & $X$ & & & $\mathrm{X}$ & $X$ & $\mathrm{X}$ & $\mathrm{X}$ & & & & $X$ & & & \\
\hline 4. & Delays of material or equipment delivery & $X$ & $X$ & & $X$ & $\mathrm{X}$ & $X$ & & & & & & & & & \\
\hline 5. & Delays in handing over the construction site to the contractor & \multicolumn{15}{|c|}{ Interviewing Experts } \\
\hline 6. & Shortage of material or equipment & $X$ & & & & & & & & $\mathrm{X}$ & & & & & & \\
\hline 7. & Shortage of skilled laborers by the contractor & & & & $X$ & $\mathrm{x}$ & & & & $X$ & $x$ & & & & $x$ & \\
\hline 8. & Weather effects & & & $X$ & & & $X$ & & & & & & & & & \\
\hline 9. & Changes of the scope/design during construction & & & $X$ & & $X$ & & & $X$ & $X$ & $X$ & $X$ & & & & $X$ \\
\hline 10. & Delays in getting work permits & \multicolumn{15}{|c|}{ Interviewing Experts } \\
\hline 11. & lack of effective communication between the parties involved & & & & & & & $x$ & & & & & & $x$ & $x$ & $x$ \\
\hline 12. & Inaccurate design drawings/documents by the designer & & & $X$ & & $\mathrm{x}$ & & & $\mathrm{x}$ & & $x$ & & $x$ & & & \\
\hline 13. & Lack of experience and knowledge of contractor staff & & & & & $\mathrm{X}$ & & & $\mathrm{X}$ & $X$ & $X$ & & & $X$ & & \\
\hline 14. & Rework due to errors during construction & & & $X$ & & & & $x$ & & & & & & & & \\
\hline 15. & Delays in progress payments by the owner & $X$ & & & & & & & $\mathrm{X}$ & & & $X$ & & & & \\
\hline 16. & Governmental and political related issues & & & & & & & & & & $X$ & & & & & \\
\hline 17. & Delays in contractor payment to sub-contractors and suppliers & & & & & & & & $X$ & & & & & $X$ & & \\
\hline 18. & Long time for approval and decision making by owner & $X$ & & $X$ & & $\mathrm{X}$ & & $X$ & & $X$ & $X$ & & & & & \\
\hline 19. & Unforeseen (unexpected) site conditions & & & & $X$ & & & & & & & & & & & \\
\hline 20. & Inappropriate construction methods & & & & & & & & & & & & $X$ & & & \\
\hline 21. & Inflation and escalation of material prices & $X$ & & & & & & & $\mathrm{X}$ & & & $X$ & $X$ & & & \\
\hline 22. & Delays related to sub-contractors' work & & & & & $\mathrm{X}$ & & & & $X$ & & & & & & \\
\hline 23. & Low productivity by contractor labor & & & & & $\mathrm{X}$ & & $x$ & $\mathrm{X}$ & $X$ & & & & & & \\
\hline
\end{tabular}




\subsection{Changes of Scope/Design during Construction}

Design change is defined as any change to the scope of the work as defined by the contract documents following the creation of legal relations between the principal and the contractor. Often the changes are not the fault of the contractors. Design changes may occur in architectural, structural, plumbing, and drainage site works or other aspects of construction.

\subsection{Delay in Getting Work Permits}

The work permit process is a key element of controlling the work and it shall be used to confirm that work is performed in a safe and environmentally sound manner. The system for the permission to work utilizes a form of permission that requires review and approval prior to the commencement of work. The purpose of the system is to verify that work between different teams working in proximity to each other is identified.

\subsection{Lack of Effective Communication between the Parties Involved}

Effective Communication involves the giving and receiving of information, signals, or messages by talk, gestures, and writing and it is one of the core competencies that all information professionals should possess.

\subsection{Inaccurate Design Drawings/Documents by the Designer}

Inaccuracies in the design drawings/documents such as having wrong dimensions, specification, and so forth can lead to rework in the engineering section and fabrication (if involved) and execution as well, which leads to time and cost overruns.

\subsection{Lack of Experience and Knowledge of Contractor Staff}

Having less experienced staff in construction work is risky, which may lead to reworking, bad quality, and schedule delays.

\subsection{Rework Due to Errors during Construction}

Errors are defined as unintended deviations from correct and acceptable practices and lead to project cost and schedule overruns, which are both unnecessary and avoidable.

\subsection{Delay in Progress Payment by the Owner}

This refers to the delay in releasing the progress payment where the payment claim is made when each stage is completed.

\subsection{Governmental and Political Related Issues}

This involves new regulations and standards that were not available during or before the signing of the contract, which impose certain requirements to be complied with and eventually affect cost or schedule.

\subsection{Delay in Contractor Payment to Sub-Contractors and Suppliers}

Delaying the payment between the main contractor and subcontractor can breach the contract between both parties and is likely to harm the project itself.

\subsection{Long Time for the Approval and Decision Making by the Owner}

Delaying the approval of some important documents or keeping the decision pending without a clear path for a long time has a definite impact on the project schedule. 


\subsection{Unforeseen (Unexpected) Site Conditions}

Unforeseen site conditions typically arise in two situations: (1) the conditions encountered at the site differ materially from those indicated in the contract, or (2) the conditions encountered at the site differ materially from those normally encountered.

\subsection{Inappropriate Construction Methods}

Sometime, there are several ways of doing one thing and there is only one right way to get it done. Using, a different method from the right one will consume time with uselessness and it can lead to health and safety incidents or lead to a bad quality product.

\subsection{Inflation and Escalation of Material Prices}

Inflation is an economic term that indicates the increase in the price of goods and services over time. Where escalation refers to the rise in the price of specific commodities, goods, or services due to a combination of inflation, supply/demand, and other effects such as environmental and engineering changes.

\subsection{Delays Related to Sub-Contractor's Work}

The main contractor is obligated as per the contract to complete the project on time regardless of the sub-contractor performance. Sometime, the main contractor is impacted due to the performance of a sub-contractor. The main contractor is responsible to coordinate between the sub-contractors if more than one exists and ensure that no clutches or delays occur because of their performance.

\subsection{Low Productivity by Contractor Labor}

Labor productivity is concerned with the amount (volume) of output that is obtained from each employee. It is a key measure of business efficiency, particularly for firms in which the production process is labor-intensive.

\section{Assessment of Factors Causing Delay in Petrochemical Projects}

The identified 23 factors were ranked through a web-based questionnaire survey. A total of 90 responses were gathered from the full population of 106 professionals working in petrochemical projects in the Eastern Province of Saudi Arabia. This section presents an assessment of the perceived level of importance of each of the 23 factors causing schedule delays for petrochemical projects.

\subsection{Characteristics of the Respondents}

The scope of this study was focused on obtaining responses from the project staff such as the project engineer, manager, supervisor, and so forth working in petrochemical projects. In the 90 responses received, there are 32 project managers, 22 project engineers, 7 construction supervisors, and the other 31 having different positions in the project department. All the responses were classified according to their experiences in petrochemical projects and arranged into four groups, which are 0 to 5 years, 5 to 10, 10 to 15, and more than 15 years, as shown in Appendix 9. A total of $44.4 \%$ of responses were from people having project experience for more than 10 years. On the other hand, $21.1 \%$ of the participants had 5 years' experience or less.

The questionnaire used for gathering the information mainly has the following four sections:

- The purpose

- Personal information of the respondent

- Evaluation of the factors causing schedule delays during the construction stage.

A brief guide and the purpose of the questionnaire described in the first section of the questionnaire. In the second section, the personal information of the respondent is required, which, 
in this case, included project managers, project engineers, or construction supervisors. In the third section, the respondents were requested to provide general information about their total experience, company, and specific experience of petrochemical projects.

Last but not the least, the fourth section, which is the main section, is the most important one. This section is named the "factor impacting construction phase". In this section of the questionnaire, the respondents were provided with a list of all 23 factors that may influence the schedule of a project. The respondents were asked to rate the factors in terms of importance and the frequency (probability) of the occurrence of that factor. The ratings used along with their corresponding weight were "very highly important" with five points, "high" with four points, "Moderate" with three points, "Low" with two points and "very low" with one point.

The questionnaire survey was conducted in the Eastern Province of Saudi Arabia. This is mainly due to two reasons. The first is the ease of access to the researcher who was located in that region. The second is the ability to answer questions raised by the respondents participating in the study due to the interview method of collecting the required data. A total of 90 respondents were gathered in this study to rate the importance of those factors and the frequency (probability) of an occurrence of the identified factor.

\subsection{Relative Importance Index (RII)}

The gathered responses were assessed, tabulated, and the relative importance index (RII) method was used to determine the relative importance of the identified factors. This deterministic method is chosen for the following reasons:

- It is easy to be understood and used by all levels of respondents regardless of their level of education

- The questionnaire survey involves a large number of factors, which makes the application of RII effective. The following equation is used to determine the relative importance index (RII)

$$
\mathrm{RII}=\frac{\Sigma \mathrm{SR}}{\mathrm{W}(\mathrm{N})}
$$

where,

$\mathrm{SR}=$ the scale of each factor based on the participant judgment (1 to 5 ) for Relative Importance $\mathrm{W}=$ the highest weight, equal to 5

$\mathrm{N}=$ the number of participants

RII varies from 1 to 0 , where a higher value means that the factor is more important

\subsection{Frequency Adjusted Importance Index (FAII)}

This method reflects the impact and the frequency in the equation resulted from the survey. The Frequency index (FI) and Relative importance index (RII) shall be calculated. To calculate FI, the following equation shall be applied:

$$
\mathrm{FI}=\frac{\Sigma \mathrm{SF}}{\mathrm{W}(\mathrm{N})}
$$

where,

$\mathrm{SF}=$ the scale of each factor based on the participant judgment (1 to 5) for the Frequency factor

$\mathrm{W}=$ the highest weight, equal to 5

$\mathrm{N}=$ the number of participants 
After calculating the FI and the RII, then the frequency adjusted importance index shall be identified using the following equation:

$$
\mathrm{FAII}=(\mathrm{RII} \times \mathrm{FI}) \times 100
$$

\subsection{Spearman's Rank Correlation}

One of the useful analysis tools that can help to achieve the desired accuracy level is Spearman's Rank Correlation Factor. It does not require the distribution to be normal, which gives this tool privilege over other tools. In this report, the Spearman's rank equation is applied in order to check the relationship between two different categories, for example, the correlation between the RII and FAII for the received responses. Furthermore, the correlation between the Owner and Contractor perspectives for the ranking of the delay factors. The value of $r$ falls in the range between +1 and -1 , where +1 indicates an agreement and while -1 indicates a disagreement.

$$
\mathrm{r}=1-\left[\frac{6 \sum \mathrm{d}^{2}}{\mathrm{n}^{3}-\mathrm{n}}\right]
$$

$r=$ the Spearman rank correlation coefficient.

$\mathrm{d}=$ the difference between two ranking by different groups/methods

$\mathrm{n}=$ the number of delay factors.

\section{Discussion of the Results}

The data for this report were collected from a survey developed through https://www. esurveycreator.com. It is an online survey service used in creating, sharing, and finally recording responses from surveys. The survey was shared by email. A total of 106 replies were received but, only 90 were completed. For this analysis, the completed responses (90) were used.

\subsection{Influencing Factors}

All the respondents rated each individual delay factor in terms of the impact level and frequency level using a scale of five points. In the survey, it was requested to evaluate the impact level of the construction project's delay and the frequency of that factor, which is how often the factor can happen in construction projects. Table 2 shows the original data of the survey, which presents the impact level (importance) and Table 3 presents the original data of the frequency values rated by the participants.

\begin{tabular}{|c|c|c|c|c|c|c|c|}
\hline \multirow{2}{*}{ S/n } & \multirow{2}{*}{ Potential Delay Factor } & \multicolumn{6}{|c|}{ Impact Level } \\
\hline & & 1 & 2 & 3 & 4 & 5 & Total Response \\
\hline 1 & Poor site management and supervision by contractors. & 1 & 4 & 16 & 37 & 32 & 90 \\
\hline 2 & Conflict between main contractor and subcontractor. & 3 & 13 & 27 & 25 & 22 & 90 \\
\hline 3 & Poor planning and scheduling of projects by the contractor. & 1 & 7 & 18 & 32 & 32 & 90 \\
\hline 4 & Delays in material or equipment delivery. & 1 & 4 & 12 & 28 & 45 & 90 \\
\hline 5 & Delays in handing over construction site to the contractor. & 1 & 6 & 31 & 30 & 22 & 90 \\
\hline 6 & Shortage of skilled laborers for the contractor. & 2 & 7 & 20 & 48 & 13 & 90 \\
\hline 7 & Weather effects. & 1 & 15 & 38 & 28 & 08 & 90 \\
\hline 8 & Changes of scope/design during construction. & 0 & 13 & 19 & 31 & 27 & 90 \\
\hline 9 & Delays in getting work permits. & 1 & 6 & 23 & 39 & 21 & 90 \\
\hline 10 & Lack of effective communication between the parties involved. & 1 & 15 & 25 & 43 & 6 & 90 \\
\hline 11 & Inaccurate design drawings/documents by the designer. & 0 & 9 & 23 & 36 & 22 & 90 \\
\hline 12 & Lack of experience and knowledge of contractor staff. & 2 & 2 & 29 & 40 & 17 & 90 \\
\hline 13 & Rework due to errors during construction. & 2 & 16 & 30 & 31 & 11 & 90 \\
\hline 14 & Delays in progress payment by owner. & 6 & 18 & 26 & 24 & 16 & 90 \\
\hline 15 & Governmental and political related issues. & 14 & 22 & 25 & 18 & 11 & 90 \\
\hline
\end{tabular}

Table 2. The raw data for the Relative Importance Index (RII). 
Table 2. Cont.

\begin{tabular}{|c|c|c|c|c|c|c|c|}
\hline \multirow{2}{*}{$\mathbf{S} / \mathbf{n}$} & \multirow{2}{*}{ Potential Delay Factor } & \multicolumn{6}{|c|}{ Impact Level } \\
\hline & & 1 & 2 & 3 & 4 & 5 & Total Response \\
\hline 16 & Delay in contractor payment to sub-contractors and suppliers. & 6 & 13 & 38 & 20 & 13 & 90 \\
\hline 17 & Long time for approval and decision making by owner. & 2 & 2 & 27 & 33 & 26 & 90 \\
\hline 18 & Shortage of materials or equipment. & 3 & 7 & 29 & 38 & 13 & 90 \\
\hline 19 & Unforeseen (unexpected) site conditions. & 2 & 15 & 35 & 29 & 9 & 90 \\
\hline 20 & Wrong construction methods. & 3 & 17 & 28 & 31 & 11 & 90 \\
\hline 21 & Inflation and escalation of material prices. & 4 & 12 & 45 & 22 & 7 & 90 \\
\hline 22 & Delays related to sub-contractors' work. & 3 & 9 & 29 & 42 & 7 & 90 \\
\hline 23 & Low productivity by contractor labor. & 4 & 8 & 24 & 44 & 10 & 90 \\
\hline
\end{tabular}

Table 3. The raw data for the Frequency Index (FI).

\begin{tabular}{|c|c|c|c|c|c|c|c|}
\hline \multirow{2}{*}{$\mathbf{S} / \mathbf{n}$} & \multirow{2}{*}{ Potential Delay Factor } & \multicolumn{6}{|c|}{ Frequency Level } \\
\hline & & 1 & 2 & 3 & 4 & 5 & Total Response \\
\hline 1 & Poor site management and supervision by contractors. & 3 & 19 & 43 & 21 & 4 & 90 \\
\hline 2 & Conflict between main contractor and subcontractor. & 11 & 29 & 38 & 8 & 4 & 90 \\
\hline 3 & Poor planning and scheduling of projects by the contractor. & 7 & 24 & 33 & 17 & 9 & 90 \\
\hline 4 & Delays in material or equipment delivery. & 4 & 17 & 40 & 20 & 9 & 90 \\
\hline 5 & Delays in handing over the construction site to the contractor. & 3 & 35 & 37 & 10 & 5 & 90 \\
\hline 6 & Shortage of skilled laborers for the contractor. & 12 & 14 & 34 & 25 & 5 & 90 \\
\hline 7 & Weather effects. & 20 & 23 & 38 & 7 & 2 & 90 \\
\hline 8 & Changes of scope/design during construction. & 4 & 27 & 39 & 16 & 4 & 90 \\
\hline 9 & Delays in getting work permits. & 3 & 17 & 32 & 22 & 16 & 90 \\
\hline 10 & Lack of effective communication between the parties involved. & 5 & 29 & 32 & 22 & 2 & 90 \\
\hline 11 & Inaccurate design drawings/documents by the designer. & 11 & 22 & 37 & 18 & 2 & 90 \\
\hline 12 & Lack of experience and knowledge of contractor staff. & 9 & 31 & 29 & 18 & 3 & 90 \\
\hline 13 & Rework due to errors during construction. & 8 & 35 & 29 & 14 & 4 & 90 \\
\hline 14 & Delays in progress payment by owner. & 25 & 30 & 25 & 6 & 4 & 90 \\
\hline 15 & Governmental and political related issues. & 37 & 29 & 15 & 6 & 3 & 90 \\
\hline 16 & Delays in contractor payment to sub-contractors and suppliers. & 14 & 28 & 38 & 5 & 5 & 90 \\
\hline 17 & Long time for approval and decision making by owner. & 6 & 21 & 37 & 19 & 7 & 90 \\
\hline 18 & Shortage of materials or equipment. & 18 & 24 & 37 & 10 & 1 & 90 \\
\hline 19 & Unforeseen (unexpected) site conditions. & 22 & 32 & 29 & 6 & 1 & 90 \\
\hline 20 & Wrong construction methods. & 26 & 32 & 26 & 5 & 1 & 90 \\
\hline 21 & Inflation and escalation of material prices. & 24 & 32 & 29 & 4 & 1 & 90 \\
\hline 22 & Delays related to sub-contractors' work. & 7 & 29 & 41 & 11 & 2 & 90 \\
\hline 23 & Low productivity by contractor labor. & 10 & 24 & 42 & 11 & 3 & 90 \\
\hline
\end{tabular}

\subsection{RII Ranking}

The gathered data were analyzed to develop the Relative Importance Index (RII) and Frequency Adjusted Importance Index (FAII). If the number is high, that means the high importance level of the cause factor and vice versa. Table 4 illustrated both RII values and the ranks of those potential delay factors rated using five scales for the impact level.

The Relative importance index (RII) equation was used to generate these values. Then, the generated values were ranked from highest to lowest to identify the top five factors having the highest RII value. The list below shows the top potential factors listed in order from the highest to lowest from the top five:

1. Delays in material or equipment delivery.

2. Poor site management and supervision by contractors.

3. Poor planning and scheduling of projects by the contractor.

4. Long time for approval and decision making by owner.

5. Delays in getting work permits. 
Table 4. The Relative Importance Index (RII).

\begin{tabular}{cccc}
\hline $\mathbf{s} / \mathbf{n}$ & Potential Delay Factor & RII & Ranking \\
\hline 1 & Delays in material or equipment delivery. & 0.849 & 1 \\
2 & Poor site management and supervision by contractors. & 0.811 & 2 \\
3 & Poor planning and scheduling of projects by the contractor. & 0.793 & 3 \\
4 & Long time for approval and decision making by owner. & 0.776 & 4 \\
5 & Delays in getting work permits. & 0.762 & 5 \\
6 & Changes of scope/design during construction. & 0.76 & 6 \\
7 & Inaccurate design drawings/documents by the designer. & 0.758 & 7 \\
8 & Lack of experience and knowledge of contractor staff. & 0.751 & 8 \\
9 & Delays in handing over construction site to the contractor. & 0.747 & 9 \\
10 & Shortage of skilled laborers for the contractor. & 0.74 & 10 \\
11 & Shortage of materials or equipment. & 0.713 & 11 \\
12 & Conflict between main contractor and subcontractor. & 0.711 & 12 \\
13 & Low productivity by contractor labor. & 0.707 & 13 \\
14 & Delays related to sub-contractors' work. & 0.691 & 14 \\
15 & Lack of effective communication between the parties involved. & 0.684 & 15 \\
16 & Rework due to errors during construction. & 0.673 & 16 \\
17 & Wrong construction methods. & 0.667 & 17 \\
18 & Unforeseen (unexpected) site conditions. & 0.662 & 18 \\
19 & Weather effects. & 0.66 & 19 \\
20 & Delays in progress payment by owner. & 0.658 & 20 \\
21 & Delays in contractor payment to sub-contractors and suppliers. & 0.647 & 21 \\
22 & Inflation and escalation of material prices. & 0.636 & 22 \\
23 & Governmental and political related issues. & 0.578 & 23 \\
\hline
\end{tabular}

\subsection{FAII Ranking}

The frequency of potential delay factors is shown in Table 5. These values were developed after applying the Frequency Index (FI) equation. Table 6 shows the Frequency Adjusted Importance Index (FAII), which is simply a combination between RII and FI. The FAII values were generated by using Equation (3). Then, the generated values were ranked from the highest to lowest to identify the top five factors having the highest FAII value. The following list shows the top potential factors listed from the highest to lowest from the top five:

1. Delays in material or equipment delivery.

2. Delays in getting work permits.

3. Poor site management and supervision by contractors.

4. Poor planning and scheduling of projects by the contractor.

5. Long time for approval and decision making by owner.

Table 5. The Frequency Importance Index (FI).

\begin{tabular}{cccc}
\hline $\mathbf{s} / \mathbf{n}$ & Potential Delay Factor & FI & Ranking \\
\hline 1 & Delays in getting work permits. & 0.67 & 1 \\
2 & Delays in material or equipment delivery. & 0.63 & 2 \\
3 & Poor site management and supervision by the contractors. & 0.61 & 3 \\
4 & Long time for approval and decision making by owner. & 0.60 & 4 \\
5 & Poor planning and scheduling of projects by the contractor. & 0.59 & 5 \\
6 & Shortage of skilled laborers for the contractor. & 0.59 & 5 \\
7 & Changes of scope/design during construction. & 0.58 & 6 \\
8 & Lack of effective communication between the parties involved. & 0.57 & 7 \\
9 & Delays in handing over construction site to the contractor. & 0.55 & 8 \\
10 & Inaccurate design drawings/documents by the designer. & 0.55 & 9 \\
\hline
\end{tabular}


Table 5. Cont.

\begin{tabular}{lccc}
\hline $\mathbf{s} / \mathbf{n}$ & Potential Delay Factor & FI & Ranking \\
\hline 11 & Lack of experience and knowledge of contractor staff. & 0.54 & 10 \\
12 & Low productivity by contractor labor. & 0.54 & 11 \\
13 & Delays related to sub-contractors' work. & 0.54 & 12 \\
14 & Rework due to errors during construction. & 0.54 & 13 \\
15 & Conflict between main contractor and subcontractor. & 0.52 & 14 \\
16 & Delays in contractor payment to sub-contractors and suppliers. & 0.51 & 15 \\
17 & Shortage of materials or equipment. & 0.49 & 16 \\
18 & Weather effects. & 0.48 & 17 \\
19 & Delays in progress payment by owner. & 0.45 & 18 \\
20 & Unforeseen (unexpected) site conditions. & 0.45 & 19 \\
21 & Inflation and escalation of material prices. & 0.44 & 20 \\
22 & Wrong construction methods. & 0.43 & 21 \\
23 & Governmental and political related issues. & 0.40 & 22 \\
\hline
\end{tabular}

Table 6. The Frequency Adjusted Importance Index (FAII) ranking.

\begin{tabular}{cccc}
\hline S/n & Potential Delay Factors & FAII & Ranking \\
\hline 1 & Poor site management and supervision by contractors. & $49.4 \%$ & 3 \\
2 & Conflict between main contractor and subcontractor. & $37.1 \%$ & 14 \\
3 & Poor planning and scheduling of projects by the contractor. & $47.1 \%$ & 4 \\
4 & Delays in material or equipment delivery. & $53.4 \%$ & 1 \\
5 & Delays in handing over construction site to the contractor. & $41.3 \%$ & 9 \\
6 & Shortage of skilled laborers for the contractor. & $43.9 \%$ & 6 \\
7 & Weather effects. & $32.0 \%$ & 18 \\
8 & Changes of scope/design during construction. & $43.7 \%$ & 7 \\
9 & Delays in getting work permits. & $51.0 \%$ & 2 \\
10 & Lack of effective communication between the parties involved. & $39.1 \%$ & 11 \\
11 & Inaccurate design drawings/documents by the designer. & $41.8 \%$ & 8 \\
12 & Lack of experience and knowledge of contractor staff. & $40.9 \%$ & 10 \\
13 & Rework due to errors during construction. & $36.1 \%$ & 15 \\
14 & Delays in progress payment by owner. & $29.8 \%$ & 19 \\
15 & Governmental and political related issues. & $23.0 \%$ & 23 \\
16 & Delays in contractor payment to sub-contractors and suppliers. & $32.9 \%$ & 17 \\
17 & Long time for approval and decision making by owner. & $46.5 \%$ & 5 \\
18 & Shortage of materials or equipment. & $35.2 \%$ & 16 \\
19 & Unforeseen (unexpected) site conditions. & $29.7 \%$ & 20 \\
20 & Wrong construction methods. & $28.6 \%$ & 21 \\
21 & Inflation and escalation of material prices. & $27.7 \%$ & 22 \\
22 & Delays related to sub-contractors' work. & $37.2 \%$ & 13 \\
23 & Low productivity by contractor labor. & $38.2 \%$ & 12 \\
\hline
\end{tabular}

In addition, this correlation factor is used to check the difference between Owner and contractor perspectives. From Table 7 , it is clearly shown that there are differences between owner ranking and contractor ranking, some high and some low, but in general, the overall ranking correlation was found to be 0.4 , which indicates an agreement between both perspectives somehow. 
Table 7. The Spearman's rank correlation factor between the Owner and Contractor.

\begin{tabular}{|c|c|c|c|c|c|c|c|}
\hline \multirow{2}{*}{$\mathrm{S} / \mathbf{n}$} & \multirow{2}{*}{ Potential Delay Factor } & \multicolumn{2}{|c|}{ Owner } & \multicolumn{2}{|c|}{ Contractor } & \multirow[b]{2}{*}{ d } & \multirow[b]{2}{*}{$\mathrm{d}^{2}$} \\
\hline & & FAII & Rank & FAII & Rank & & \\
\hline 1 & Poor site management and supervision by contractors. & $54.49 \%$ & 2 & $42.26 \%$ & 6 & -4 & 16 \\
\hline 2 & Conflict between main contractor and subcontractor. & $41.47 \%$ & 9 & $30.27 \%$ & 20 & -11 & 121 \\
\hline 3 & Poor planning and scheduling of projects by the contractor. & $49.92 \%$ & 3 & $42.01 \%$ & 7 & -4 & 16 \\
\hline 4 & Delays in material or equipment delivery. & $57.29 \%$ & 1 & $47.07 \%$ & 4 & -3 & 9 \\
\hline 5 & Delays in handing over construction site to the contractor. & $40.26 \%$ & 11 & $41.46 \%$ & 8 & 3 & 9 \\
\hline 6 & Shortage of skilled laborers for the contractor & $49.45 \%$ & 4 & $36.77 \%$ & 11 & -7 & 49 \\
\hline 7 & Weather effects. & $29.40 \%$ & 18 & $35.83 \%$ & 13 & 5 & 25 \\
\hline 8 & Changes of scope/design during construction & $44.06 \%$ & 7 & $43.01 \%$ & 5 & 2 & 4 \\
\hline 9 & Delays in getting work permits. & $45.95 \%$ & 5 & $57.70 \%$ & 1 & 4 & 16 \\
\hline 10 & Lack of effective communication between the parties involved. & $40.09 \%$ & 12 & $37.32 \%$ & 10 & 2 & 4 \\
\hline 11 & Inaccurate design drawings/documents by the designer. & $37.87 \%$ & 13 & $47.40 \%$ & 3 & 10 & 100 \\
\hline 12 & Lack of experience and knowledge of contractor staff. & $41.47 \%$ & 9 & $35.72 \%$ & 14 & -5 & 25 \\
\hline 13 & Rework due to errors during construction. & $37.17 \%$ & 14 & $34.52 \%$ & 15 & -1 & 1 \\
\hline 14 & Delays in progress payment by owner. & $23.81 \%$ & 22 & $39.08 \%$ & 9 & 13 & 169 \\
\hline 15 & Governmental and political related issues. & $23.83 \%$ & 21 & $22.14 \%$ & 23 & -2 & 4 \\
\hline 16 & Delays in contractor payment to sub-contractors and suppliers. & $36.04 \%$ & 15 & $28.27 \%$ & 21 & -6 & 36 \\
\hline 17 & Long time for approval and decision making by owner. & $45.32 \%$ & 6 & $48.48 \%$ & 2 & 4 & 16 \\
\hline 18 & Shortage of materials or equipment. & $34.08 \%$ & 16 & $36.39 \%$ & 12 & 4 & 16 \\
\hline 19 & Unforeseen (unexpected) site conditions. & $29.61 \%$ & 17 & $30.07 \%$ & 20 & -3 & 9 \\
\hline 20 & Wrong construction methods. & $29.14 \%$ & 19 & $28.21 \%$ & 22 & -3 & 9 \\
\hline 21 & Inflation and escalation of material prices. & $25.05 \%$ & 20 & $32.08 \%$ & 16 & 4 & 16 \\
\hline 22 & Delays related to sub-contractors' work. & $41.25 \%$ & 10 & $31.53 \%$ & 18 & -8 & 64 \\
\hline \multirow[t]{3}{*}{23} & Low productivity by contractor labor. & $42.90 \%$ & 8 & $31.73 \%$ & 17 & -9 & 81 \\
\hline & Total & & & & & & 815 \\
\hline & Spearman rank correlation coefficient & & & & & & 0.4 \\
\hline
\end{tabular}

\subsection{Contribution of the Experts to the Results}

After a review of past literature, a list of 23 delay factors was produced and presented in a questionnaire survey. The survey was distributed to various experts in the field of the construction industry. Then, 90 respondents evaluated the twenty-three (23) delay factors based on importance (the delay impact on construction project) and frequency (how often the factor is implemented or considered). The gathered data of 90 complete responses were analyzed using different ranking methods such as the Relative Importance Index (RII), Frequency Index (FI), and Frequency adjusted Importance Index (FAII). In terms of importance, we used Equation (1) to find the RII and found the top important factors to be the delay in material or equipment delivery, Poor site management and supervision by contractors, Poor planning and scheduling of projects by the contractor, Long time for approval and decision making by owner and Delay in getting work permits.

On the other hand, using Equation (2) to find the top 5 frequent factors (FI), which found to be Delay in getting work permits, Delay of material or equipment delivery, Poor site management and supervision by contractors, Long time for approval and decision making by owner, Poor Planning and Scheduling of Projects by the Contractor and Shortage of skilled laborers. Ultimately, the best way is to find the top 5 in terms of importance and frequency, is to use Equation (3) which is Frequency Adjusted Importance Index (FAII) since there is agreement between owner and contractor for those factors. Therefore, the top five as per FAII found to be Delay of material or equipment delivery, Delay in getting work permits, Poor site management, and supervision by contractors, Poor Planning and Scheduling of Projects by the Contractor, and Long time for approval and decision-making by owner. From Table 6, it can be concluded that the factor which is considered the most significant is the Delays in material or equipment delivery (53.4\%). In fact, this a fixed risk for all projects regardless of the type and magnitude. If the required material is related to an activity within the critical path, then this will affect the whole project schedule and cost as the assigned resources will be idly waiting in standby for the materials. The second critical factor based on the survey is Delays in getting work permits $(51.0 \%)$. This factor was not highlighted during the literature review but found to be the second critical in the list. In fact, this is more applicable for petrochemical companies, where the permits are issued 
on a daily basis and different work permits for different type of activities such as hot work, cold work, confined space entry, and so forth. Indeed, delaying the issuance of the work permit has a negative impact on the project completion time, especially for those activities in the critical path. Poor site management and supervision by contractors $(49.4 \%)$ was seen to be the third critical factor. This is true as poor management is always a risk for any project. Poor management can affect the project schedule by not managing the critical activities and assign the required resources on time, reporting the progress and taking the corrective action timely. Furthermore, the project cost can be also be impacted if the cash flow is not managed and the resources are not utilized effectively in order to avoid idle time. On the other hand, good project management can have a positive impact on both the cost and schedule.

The fourth critical factor was found to be the poor planning and scheduling of projects by the Contractor (47.1\%). Indeed, failure in planning is just planning for failure. Poor planning and scheduling is a result of underestimating the activity duration, ignoring the productivity factor, overconfidence, and so forth. Subsequently, the overall project cost and the schedule are affected. Long time for approval and decision making by owner $(46.5 \%)$ was found to be the fifth critical factor. In reality, delaying owner decisions or making changes to the project can easily hinder the ability of a construction project to finish on time. Many extensions of time and variation order claims are raised by both consultants and contractors based on owner decisions. On the other hand, the top least critical factors were found to be Governmental and political related issues (23\%), Inflation and escalation of material prices $(27.7 \%)$, Wrong construction methods (28.6\%), Unforeseen (unexpected) site conditions $(29.7 \%)$ and Delays in progress payment by owner $(29.8 \%)$.

\section{Recommendation}

\subsection{Owner}

Out of five critical factors, two were found to be caused by the owner-the Delay in getting work permits and the Long time for approval and decision making by the owner. Delaying the work permit was found to be the second highest overall. In fact, it is critical in a construction project in petrochemical plants like SABIC as the permit is issued on a daily basis and by different people depending on the shift arrangement. In addition, the priority always goes to maintenance activities when it comes to permitting issuance. Therefore, based on the best practice and previous experience, it is strongly recommended to assign a dedicated work permit issuer for this project. The best time for such an assignment is during the construction kick-off meeting to have a full alignment for the work permit required prior to the starting of the construction activity. The second factor by the owner is Long time for approval and decision-making, which was found to be the least critical among the top five. Thus, the owner needs to provide assured decisions with correct information when it is required in order to avoid any decisions that may potentially delay the work. Indeed, based on the nature and the complexity of the project, the Project team shall be assigned according to their Key Technical Competency (KTC) and seniority. Furthermore, if a certain expertise is unique and required, then a consultant or third party shall be hired at an early start even prior to the design stage.

Regarding the other factors, which caused mainly by the contractor, the owner can still provide support to avoid those factors. The Delays in material or equipment delivery was found to be the highest critical factor among the top five. In fact, though the contractor causes this, the owner can still support in avoiding this by ensuring the purchase order $(\mathrm{PO})$ issuance for all long lead items and keep monitoring the delivery status on a monthly or weekly basis as required. Another example where the factor is mainly caused by the contractor but able to be supported by the owner is Poor site management and supervision by contractors. In fact, the owner can request a CV from all the project management persons and conduct interviews to ensure they have the required skills and are fit for this project. For poor planning and scheduling, the owner can thoroughly review the project schedule and challenge all unrealistic durations, whether positive or negative. 


\subsection{Contractor}

The majority of the project's delay factors are caused by the contractor. In this report, three out of five critical factors are caused by contractors. The highest critical factor in the top five is caused by the contractor (Delays in material or equipment delivery). This is critical and always risky in every project. It is recommended that the contractor start the placement of all purchase orders of long lead items after the contract is signed. Additionally, a special tracking mechanism and monitoring like SPI (Schedule Performance Index) for that the long lead items must be performed. The second potential delay factor caused by the contractor was Poor site management and supervision. It is a fact that improper site management is really a potential risk in each project and can cause a chronic issue. Thus, the contractor is responsible for hiring qualified people having enough experience to handle the project. In addition, providing the required training is also essential to keep them updated with the latest tools and techniques used in construction management.

Poor planning and scheduling was found to be the third potential delay caused by contractors and ranked number four among the common top five critical factors. In reality, planning refers to the planning of different stages and activities such as mobilization planning, construction planning (sequence of activities), risk planning, commissioning planning, start-up planning, and so forth. The contractor should pay attention to the factors affecting planning and scheduling such as unexpected events and the production rate of used resources during the development of the schedule baseline. In addition, very close monitoring shall be done for the project baseline to check for any variation, and then corrective action shall be taken in order to meet the timeline. The corrective action can be through activities crashing (project accelerating) or changing some sequence of certain activities.

\section{Conclusions}

Petrochemicals have become essential materials in our daily life. The petrochemicals industry is similar to any other Oil and Gas industry. It invests very huge capital annually on different projects in nature; expansion, revamp, legal, safety, and so forth. Those projects are impacted mostly during the construction phase, which leads to either cost overruns, time delays or both, and causes millions of Saudi Riyals of losses. The potential factors causing cost overruns or schedule delays were identified from literature reviews and people having experience in this class of projects. Then, the survey was designed, developed, and distributed among the owner and contractors' employees to check the relevance of those factors on those projects.

All completed responses (90) were analyzed using the Relative Importance Index (RII), Frequency Index (FI), and Frequency Adjusted Importance Index (FAII). The adapted ranking was FAII as it combines both importance and frequency measures. Based on FAII, it was found that the top five critical factors are the Delays in material or the equipment delivery (1st), Delays in getting work permits (nd), Poor site management and supervision by contractors (3rd), Poor Planning and Scheduling of Projects by the Contractor (4th), and Long time for approval and decision making by owner (5th). On the other hand, the least five effective factors are governmental and political related issues (23rd), Inflation and escalation of material prices (2nd), Wrong construction methods (21st), Unforeseen (unexpected) site conditions (20th), and Delays in progress payment by owner (19th).

Eventfully, several recommendations were generated for both owners and contractors. For example, from the owner side, to dedicated work permit issuers, the involvement of experienced people in the project to help in making the decision, and so forth. From the contractor side, to provide monitoring and control tools like SPI for material delivery, to hire qualified and experience people for site management, and so forth. Ultimately, the objective of this report is already met by assessing the potential factor and providing the required recommendations to help in avoiding those factors from happening. 
Author Contributions: The authors A.R.A. and A.A. contributed to all parts of the research starting from literature review, identifying factors to be included in the study, data collection, analysis, discussion and writing-Original draft reparation, writing-review and Editing.

Funding: This research received no external funding.

Acknowledgments: The authors would like to thank KFUPM for the facilities provided to carry out this research.

Conflicts of Interest: The authors declare no conflict of interest.

Appendix: Survey Sample.

\section{Critical Factors Causing Schedule Delay during Construction phase of Petrochemical Projects in Saudi \\ Arabia}

\section{Page 1}

The objective of this survey is to identify the critical factors affecting projects' construction phase and help to generate recommendation in order to improve petrochemical business.

\section{General Information and Background}

Please Select Your Company From the Below Options *

Owner

Contractor

Other

What is Your Job Title in Your Organization *

Project Manager

Project Engineer

Construction Supervisor

Other

Please Select Your Total Experience in Executing Petrochemical Projects *

1 - 5 Years

$5-10$ Years

$10-15$ Years

More than 15 Years 


\section{In Next Section, You will Explore 23 Potential Factors Impacting Project During Construction Stage. From Your Experience in Petrochemical, Kindly Evaluate Each Factor Based on Impact Level" and Frequency Level**.}

* Impact level means how bad this factor can impact Project Cost or Schedule.

* Frequency Level means how often this factor can happen.

\section{Potential Factors}

1. Poor Site Management and Supervision by Contractors. *

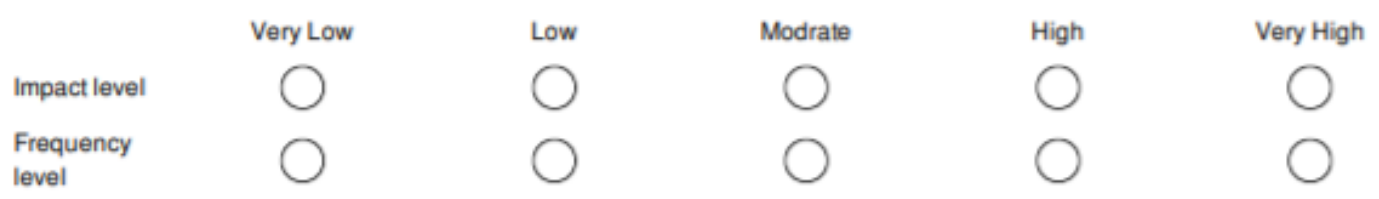

2. Conflict Between Main Contractor and Subcontractor. *

$\begin{array}{lcccc}\text { Impact level } & \text { Very Low } & \text { Modrate } & \text { High } & \text { Very High } \\ \begin{array}{l}\text { Frequency } \\ \text { level }\end{array} & \bigcirc & 0 & O & 0\end{array}$

3. Poor Planning and Scheduling of Projects by Contractor. *

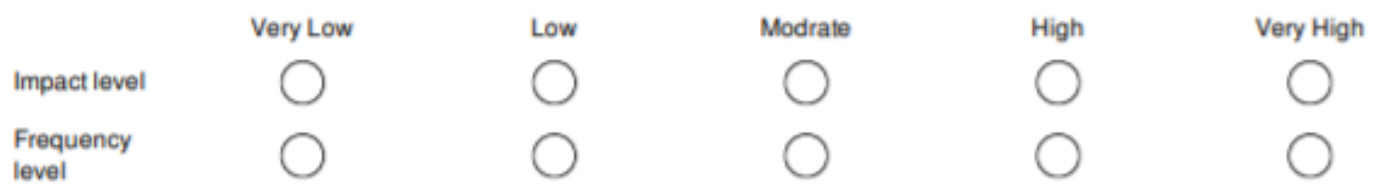

4. Delay in Material and Equipment Delivery. *

$\begin{array}{lcccc}\text { Impact level } & \text { Very Low } & \text { Modrate } & \text { High } & \text { Very High } \\ \text { Frequency } \\ \text { level }\end{array}$

\section{References}

1. Srdić, A.; Šelih, J. Delays in Construction Projects: Causes and Mitigation. Organ. Technol. Manag. Constr. 2015, 7. [CrossRef]

2. Gunduz, M.; AbuHassan, M. Causes of Construction Delays in Qatar Construction Projects. J. Civ. Environ. Struct. Constr. Archit. Eng. 2016, 10, 531-536.

3. Samarghandi, H.; Tabatabaei, S.; Taabayan, P.; Hashemi, A.; Willoughby, K. Studying the reasons for delay and cost overrun in construction projects: The case of Iran. J. Constr. Dev. Ctries. 2016, 21, 51-84. [CrossRef]

4. Doloi, H.; Sawhney, A.; Iyer, K.; Rentala, S. Analysing factors affecting delays in Indian construction projects. Int. J. Proj. Manag. 2012, 30. [CrossRef] 
5. Tan Phat Nguyen Nicholas Chileshe. Revisiting the construction project failure factors in Vietnam. Built Environ. Proj. Asset Manag. 2015, 5, 398-416. [CrossRef]

6. Salama, M.; El Hamid, M.A.; Keogh, B. Investigating the causes of delay within oil and gas Projects in the U.A.E. In Proceedings of the 24th Annual ARCOM Conference, Cardiff, UK, 1-3 September 2008; Dainty, A., Ed.; Association of Researchers in Construction Management: Edinburgh, UK, 2008; pp. 819-827.

7. Khan, S. An Analysis on Critical Causes of Delays in Oil \& Gas Construction Projects. In Proceedings of the Project Management National Conference: Architecting Project Management for Redefining India, Bangaluru, India, 10-12 September 2015.

8. Alinaitwe, H.; Apolot, R.; Tindiwensi, D. Investigation into the Causes of Delays and Cost Overruns in Uganda's Public Sector Construction Projects. J. Constr. Dev. Ctries. 2013, 18, 33-47.

9. Rao, B.P. Delay Analysis of Construction Projects. J. IT Econ. Dev. 2016, 7, 15-24.

10. Ruqaishi, M.; Bashir, H.A. Causes of Delay in Construction Projects in the Oil and Gas Industry in the Gulf Cooperation Council Countries: A Case Study. J. Manag. Eng. 2013, 31. [CrossRef]

11. Raykar, P.; Ghadge, A.N. Analyzing the Critical Factors Influencing the Time Overrun and Cost Overrun in Construction Project. Int. J. Eng. Res. 2016, 5, 21-25.

12. Othuman Mydin, M.O.; Sani, N.M.; Taib, M.; Alias, N.M. Imperative Causes of Delays in Construction Projects from Developers' Outlook. EDP Sci. 2014. [CrossRef]

13. Hwang, B.G.; Leong, L.P. Comparison of schedule delay and causal factors between traditional and green construction projects. Tech. Econ. Dev. Econ. 2013, 19, 310-330. [CrossRef]

14. Hwang, B.G.; Zhao, X.; Ng, S.Y. Identifying the critical factors affecting schedule performance of public housing projects. Habitat Int. 2013, 214-221. [CrossRef]

15. Hwang, B.G.; Yang, S. Rework and schedule performance: A profile of incidence, impact, causes and solutions. Eng. Constr. Archit. Manag. 2014, 21, 190-205. [CrossRef]

(C) 2018 by the authors. Licensee MDPI, Basel, Switzerland. This article is an open access article distributed under the terms and conditions of the Creative Commons Attribution (CC BY) license (http:/ / creativecommons.org/licenses/by/4.0/). 